\title{
A STUDY ON CONTRACTUAL INFORMATION SHARING SYSTEM
}

\author{
Yie-Ting Chen, Ming-Teh Wang*, Shang-Hsien Hsieh \\ Department of Civil Engineering, National Taiwan University, Taipei, Taiwan \\ *Corresponding author; E-mail address: mtwang@ce.ntu.edu.tw
}

\begin{abstract}
Traditionally, the contractually required data are delivered with paper format, which could cause many problems such as waste of papers, difficulties in managing documents, error-prone in data processing, etc. If the owner and contractors in a construction project do not share the information specified in their contract efficiently and consistently, their communication cannot be effective and correct. Such problems can be improved by using advanced information technologies. This paper presents the concept of a model-based CITIS system for establishing a contractual sharing information system. By making use of Object-Oriented techniques, this research then proposes Contractual Document Information Model (CDIM).
\end{abstract}

Keywords: Document Management, Contractual Information System, CITIS, Information Sharing, Construction CALS

\section{INTRODUCTION}

A construction project can be divided into the following five phases: planning, design, bidding, construction, and operation and maintenance. The participants in the project need to communicate and transfer information with each other, either within a phase or between two phases. For example, owners have to communicate with design consultants or constructors. The information transfer among participants in a phase can be called horizontal information transfer. How the information is transferred and what documents are delivered are typically defined in design contract or construction contract.

The information transfer in construction phase is particularly complex. In construction phase, the participants include owner, architect/engineer, and constructor. The owner contracts with contractors in the bidding phase. The responsibilities and obligations of these two parties are defined in the contract. For example, constructors are required to deliver necessary documents or information to the owner in specified dates and format. These contractually required data are important tools for the owner to keep track on construction progress and qualities.

Traditionally, contractually required data are delivered with paper format, which could cause following problems: waste of paper, difficulties in managing documents, error-prone in data process, information lost during delivery, and inconsistency of documents. If owners and contractors do not share information efficiently and consistently, their communication cannot be effective and correct. However, such problems can be greatly improved by using advanced information technologies.

This paper proposes a mechanism of information sharing among owners and contractors. and then designs a conceptual system that can be used to help owners and contractors to share contractually required documents and information efficiently and productively.

\section{RELATED RESEARCH}

Many computer programs have been developed to help owners or contractors process their data during project delivery processes. However, an electronic or computer system does not mean it can solve all the problems as mentioned above. For example, the issues about information sharing and effective communication between participants are often neglected.

To provide an electronic contractually required information service is an example of how we can better apply information technologies to improve the communication between owners and contractors. Such information service systems can not only provide effective information communication, but also form a better integrated information architecture to increase the level of construction automation along a construction life cycle.

In order to improve the efficiency and accuracy of delivery of contractually required data, U.S. Department of Defense (DoD) has proposed a 
concept named Contractor Integrated Technical Information Service (CITIS), which is a contractordeveloped service that provides information to owners. The original CITIS concept was developed by the U.S. DoD in 1993[1]. They define CITIS as " $A$ contractor developed service which provides electronic access to and/or delivery of contractually required Contract Data Requirements List (CDRL) data to users." The term CDRL refers to a list of contractually specified data that the owner (USA Government, in this case) requires. An owner is the primary user of CITIS system. An owner accesses to data through service interfaces that CITIS provides. Contractors are the secondary users of CITIS system. Contractors are responsible to put required data into the CITIS system before the appointed time. Although the concept of CITIS is developed from military, it is suitable for the project that has mounts of documents to review and deliver among project participants.

CITIS has the concept that "data created once but used many times," which is in parallel to the basic philosophy of Continuous Acquisition LifeCycle Support (CALS) [2]. It stores electronic documents and delivers documents via network to prevent producing copies of document and delivery lost. The U.S. DoD's document, MIL-STD-974, is the original standard of CITIS. It defines the required services and functions of a CITIS system. Figure 1 shows the architecture of a CITIS system. The primary advantages of CITIS systems are as follow [3]:

1. Reducing the amount of delivered documents and paper waste.

2. Improving the accuracy and timeliness of documents

3. Improving the management efficiency of review comments and tracing of review status

4. Reducing the time in review process

5. Keeping document in consistency

6. Helping participants to sharing data and information.

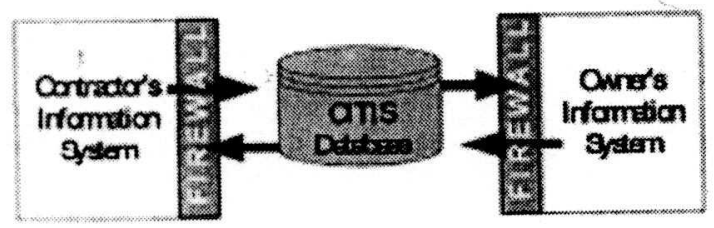

Figure 1. Architecture of CITIS system

However, CITIS does not specify how to implement and what the exchange format of delivered documents should be. Therefore, many versions of CITIS system have been developed by different interest groups to adapt their needs. For example, Nippon (Japan) CALS program has researched how to improve information sharing among multiple enterprises through CITIS [4].
However, these systems usually focus on how to store and deliver data. They seldom consider that how to integrate with other information systems. As a result. these systems are difficult to share information with other applications along a construction project life cycle. To avoid this weakness, a theoretical framework to provide CITIS system with the basis of integration with other systems is needed.

\section{MODEL-BASED ENGINEERING AND AEC INFORMATION MODEL}

The participants in a construction project exchange their information primarily via documents with paper or electronic format. Thus document data flow is the backbone of data transfer between the participants in project delivery process. This document-based engineering has provided us a fundamental model for project data transfer. Since the current evolution of information technology and the requirement of information integration, the $\mathrm{AEC}$ industry tends to apply model-based engineering instead[5]. Model-based engineering models physical construction projects as an abstract information model, which in turn is formulated and processed in computer applications. Furthermore, it replaces documents with information model for data transfer between project phases and the participants.

The fundamental idea of model-base engineering is an integrated information core model that can be used to provide the basis for the information exchange among the various professionals in the AEC industry. Within this core model, the professionals in each discipline refine their parts and perform their tasks accordingly.

Figure 2 sketches the concept of information model integrated with different disciplines. The most significant point of this model is that all shared information is referred to the integrated information core model for data storage and data reuse. The ability to share and reuse information is the key advantage of the integrated model. It keeps information consistent and reduces the difficulties in maintaining correct formats from one system to another. It also helps the linkage of its component systems. The integrated model is formed to reflect the characteristics of projects along their life cycles.

Many experts have developed their integrated information model such as COMMIT Information Management Model (CIMM)[6] and Integrated Construction Information Model (ICIM)[7]. International Standardization Organization (ISO) has proposed a standard model called STandard for the Exchange of Product (STEP). International Alliance for Interoperability (IAI) develops the Industry Foundation Class (IFC) [8]. These models can be applied to establish the foundation of integrated systems for the AEC industry. Consequently, many 
computer applications have been developed based on these models. However, a few of them are focusing on document reviewing and data delivery, which are required functions in a contractual information sharing system.

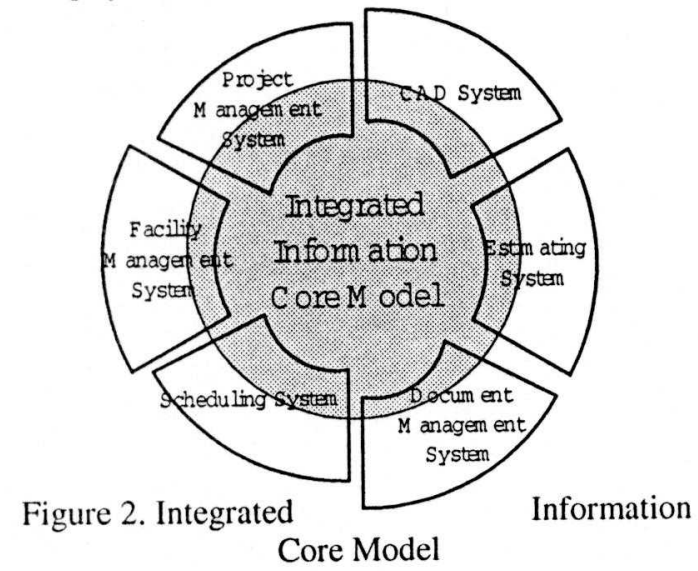

\section{MODEL-BASED CITIS SYSTEM}

To provide the ability of information sharing with other systems for contractually required data, we can develop a system by integrating The concept of CITIS and model-based engineering. This system, called model-based CITIS system, has to consider the following issues: what information we need to manage, what functions and services it should offer.

\subsection{Document Review and Request Process}

The contractually required information and data are generated form many processes in various construction phases, such as payment request and estimate process, change order process, progress report, material management and so on. To review or to monitor the construction progress, the owner needs to access to these data in each process. In general, the review process is as follows:

1. The contractor delivers contractually required data to the owner or the representative of supervision before the appointed time specified in contract.

2. The supervision representative approves the data and delivers it to the owner.

3. After the owner approves, he keeps a copy of the data and sends it back to the contractor. If the owner, supervision representative, and contractor have gaps or conflicts in the construction process, they could refer to related data or documents to make their responsibilities clear.

Therefore, CITIS system should provide such functions as:

1. The contractor can put the required data into the system.
2. The owner can have the access to the required data from the system.

3. Authorized participants can track the status of documents stored in the system.

4. Authorized users can download the documents and data they needed.

5. Authorized users can view electronic documents in the system and add their comments.

Some standard CITIS functions and services are listed in Tablel.

\subsection{Contractual Document Information Model}

Before Model-based CITIS System can be integrated into the industrial integrated information core model as shown in Figure 2, it needs to build its own information model. This subsection discusses a Contractual Document Information Model proposed by this work.

Table 1. CITIS suggested services and functions

\begin{tabular}{|c|l|}
\hline CITIS Service & Information Service \\
& Data Configuration Management \\
& CITIS Security \\
& Data item index \\
& Data Exchange Standards \\
\hline CITIS Core & Acknowledge \\
Function & Approve or disapprove \\
& Comment \\
& Notice to Delivery \\
& Receive \\
& Search \\
& Store \\
& View \\
\hline CITIS Tailorable & Application \\
Function & Archive \\
& Combine \\
& Download \\
& Edit \\
& Forward \\
& Package \\
& Query \\
& Sort \\
& User Group \\
\hline
\end{tabular}

The documents generated in construction process can be divided into two categories: instructing document, and recording document. Instructing document has instructional information that contractors and other participants have to follow to perform their tasks. Therefore, the information that keeps in documents is original. They are not reflections of other construction components. In opposite, recording documents are only reports, reflections, records of some other components, or some facts that have happened. They are generated from these facts or other components and therefore 
are not original. Some documents associated with these two are listed in Table 2.

Table 2. Example of Recording and Instructing Documents

\begin{tabular}{|l|l|}
\hline Category & Documents \\
\hline $\begin{array}{l}\text { Recording } \\
\text { Document }\end{array}$ & $\begin{array}{l}\text { Reports (site layout progress reports, } \\
\text { QA/QC reports, safety records, } \\
\text { construction progress reports), } \\
\text { Drawings, } \\
\text { Payment request, } \\
\text { Schedule }\end{array}$ \\
\hline $\begin{array}{l}\text { Instructional } \\
\text { Document }\end{array}$ & $\begin{array}{l}\text { Plans (safety plan, QA/QC plan, } \\
\text { accident prevention plan, } \\
\text { environmental control plan, } \\
\text { affirmative action plan, significant } \\
\text { deficiency action plan) } \\
\text { Specifications }\end{array}$ \\
\hline
\end{tabular}

We have to divide these two categories of documents when building the information model. Trace the information in documents back to what they exactly belong to and assign the information as properties on it are two tasks that we need to identify before we can build them in the Model-Based CITIS system. In other words, recording documents can be generated dynamically from other components in the system. The information in instructing documents can be grouped into one or some components representing the document.

To build a Model-Based CITIS system, this study applies object-oriented analysis method to find out the entities that are needed in the Contractual Document Information Model (CDIM). The objects in the model are abstractions of physical construction project components. Their relationships are established in accordance with actual construction environment. Table 3 shows the objects in this model while Figure 3 represents the relationship structure of these objects in Express-G format.

Currently, our research team has decided to use eXtensible Markup Language (XML) as the data format to represent the information carried in documents. XML is a subset of Standard Genelization Markup Language (SGML). With the characteristics of platform-independent and being able to be parsed on the web browser, XML is a suitable standard tool for document management and information sharing [9].

The next step of this system is to connect with industrial information core model and promote information sharing with other applications in the AEC industry. We now select part106, Building Construction Core Model (BCCM), of STEP as the integrated information core model to fulfill the capabilities of information sharing.
Table 3. Some Entities of Contractual Document Information Model

\begin{tabular}{|l|l|}
\hline \multicolumn{1}{|c|}{ Class } & \multicolumn{1}{|c|}{ Description } \\
\hline ReqDoc & $\begin{array}{l}\text { Represents contract required } \\
\text { documents. }\end{array}$ \\
\hline B_Project & $\begin{array}{l}\text { Represents construction project. } \\
\text { which holds the information } \\
\text { belongs to a project. }\end{array}$ \\
\hline ReviewCmt & $\begin{array}{l}\text { Any required document can be } \\
\text { added with comment by reviewers }\end{array}$ \\
\hline CDRL & $\begin{array}{l}\text { Represents Contract Data } \\
\text { Requirement List. It keeps a list of } \\
\text { owner's required documents. }\end{array}$ \\
\hline Dateltem & $\begin{array}{l}\text { Represents the date of significant } \\
\text { affair in a project, like date of } \\
\text { notice to proceed, date of } \\
\text { completion. }\end{array}$ \\
\hline R_Budget & \begin{tabular}{l} 
Represents the budget of a project. \\
\hline $\begin{array}{l}\text { R_ChangeO } \\
\text { rderBudget }\end{array}$
\end{tabular} $\begin{array}{l}\text { Represents the change order budget } \\
\text { of a project. }\end{array}$ \\
\hline BudgetItem & $\begin{array}{l}\text { Represents the estimating item in } \\
\text { each budget. }\end{array}$ \\
\hline
\end{tabular}

\section{CONCLUSIONS}

This paper presents a concept of model-based CITIS system for establishing a contractual sharing information system. By making use of the techniques of Object-Oriented paradigm, the research then proposes Contractual Document Information Model (CDIM). The information originally stored in documents becomes the attributes of objects in CDIM. In other words, users of CDIM can view the information in their own way and, if needed, retrieve the information into their computer application for further processing. CDIM can reduce the problems that document-based system could occur, and thus increase the opportunities of data sharing, data reusability, and data integrity.

\section{ACKNOWLEDGMENTS}

This ongoing project is supported by the National Science Council of Republic of China under Grant No. NCS-88-2211-E002-040.

\section{REFERENCES}

[1]U.S. Department of Defense(1993), "MIL-STD974, Contractor Integrated Technical Information Service (CITIS).“

[2]Wang, M.-T. (1997), "Development of 
Construction CALS." ASCE Construction Congress V. Minneapolis, MN, Oct.5-8.

[3]U.S. Department of Defense(1997), "Program Manager Desktop Guide for Continuous Acquisition and Life-Cycle Support (CALS) Implementation."

[4] Youichi Asahi, Hiroyuki Kajihara, Tomiyasu Ichimura, Naoto Kiyono, and Hidemi Oono (1997). "Information Sharing Among Multiple Enterprises Through CITIS," Proceedings of CALS Expo International 1997. Tokyo. pp.59-68 (in Japanese).

[5]Michael J. O'Connor (1998), "Model-based Collaborative 3 engineering: An Owner's Perspective". Journal of Computing in Civil Engineering, ASCE, Vol.12, No.2, pp.57-59

[6]Yacine Rezgui, Grahame Cooper, and Peter Brandon (1998), "Information Management in a Collaborative Multiactor Environment: The COMMIT Approach," Journal of Computing in Civil Engineering, ASCE, Vol.12, No.3, pp.136-144
[7]Annette L. Stumpf. Rajaram Ganeshan. Sangyoon Chin, and Liang Y. Liu (1996), "Object-oriented Model for Integrating Construction Product and Process Information," Joumal of Computing in Civil Engineering. ASCE, Vol.10. No. 3, pp.204-212.

[8]Thomas Froese (1996). " Models of Construction Process Information," Journal of Computing in Ciril Engineering, ASCE, vol. 10, No. 3, pp.183-193.

[9]Ellioote Rusty Harold (1998), XML: Extensible Markup Language. IDG Books Worldwide, Inc. Foster City, CA. 


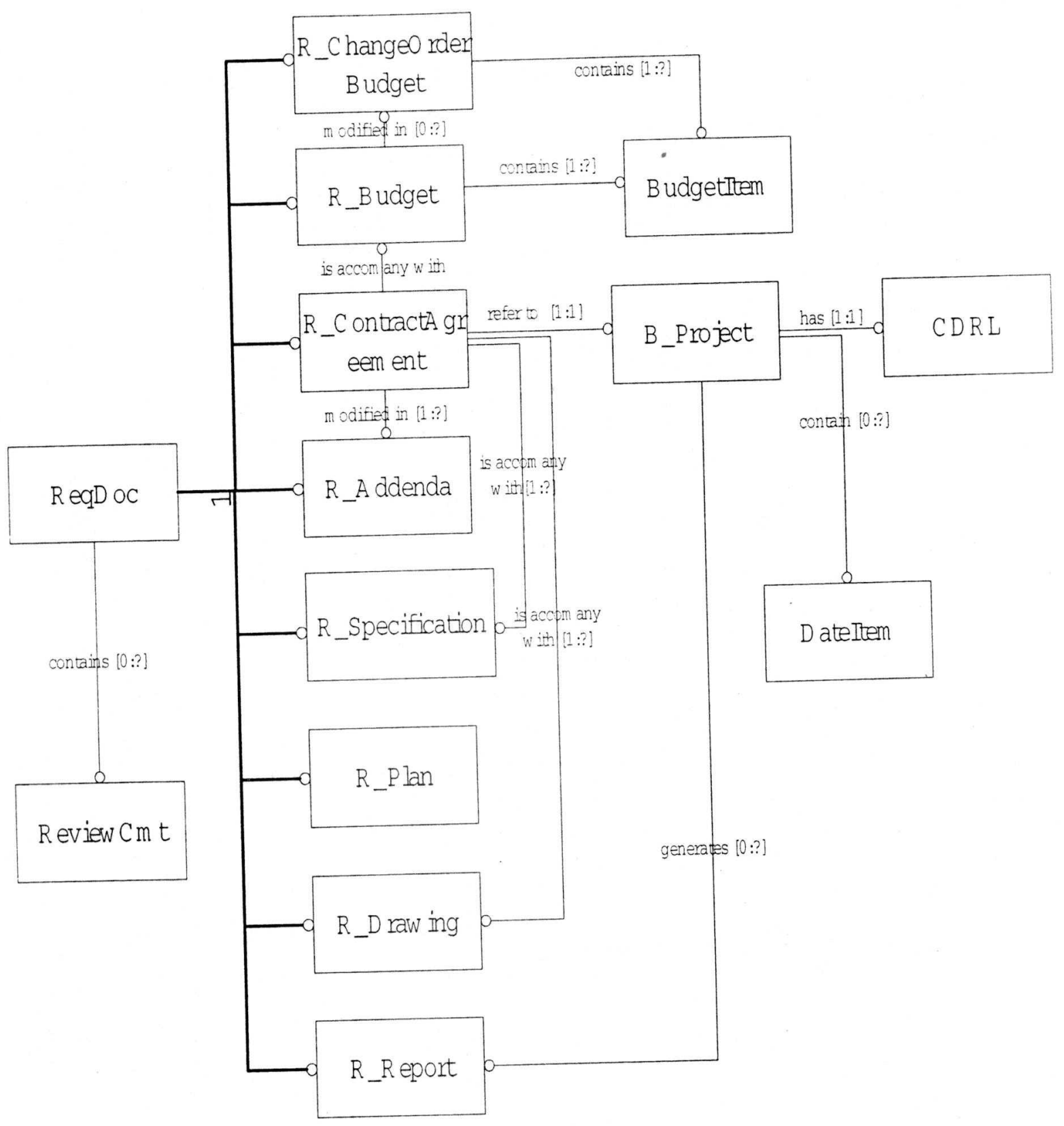

Figure 3. Contractual Document Information Model (Express-G) 